\title{
Epidemiological and Retrospective Survey of Pancreatic Cancer in Ilam City During a 10 Years Period (from 1385 till 1394)
}

\author{
Hamed Zarei ${ }^{1}$, Hamed Tavan²
}

${ }^{1}$ Department of Radiology Technology, Allied Medical Faculty, Shahid Beheshti University of Medical Sciences,Tehran, Iran. ${ }^{2}$ Faculty of Nursing and Midwifery, Prevention of Psychosocial Injuries Research Center, Ilam University of Medical Sciences, Ilam, Iran.

\begin{abstract}
Background: one of the most killing cancers globally and the fourth most relevant cancer, the pancreatic cancer has a great numbers of victims every tear, therefore, the goal of this study was to investigate the rate of incidence among residents of ilam in time span of 10 years, from 1385 till 1394. Materials and Methods: this is a retrospective study during 1385 till 1394 in Ilam city. Our source of patients was the afflicted patients. The sample size and the statistical society of research were determined based on census. The research materials included of two types first included the demographic information of patients (age, gender, tumor type, level of education, residency, smoking and lipid profile) and the second part was some information about the pancreatic cancer (anatomical site, pathologic findings and lipid profile).using SPSS version 19, the data was analyzed. Results: the statistical society included 25 individuals afflicted with pancreatic cancer in which the most prevalent age group was men older than 70 years (60 years) (31.3\%). Furthermore, as time went on, the number of new cases increased. Conclusion: the risk factors for occurring the cancer were the age group greater than 70 years, being male, lower educational situation, unemployment, living in an urban areas, smoking, hereditary, hyperlipidemia (LDL, TG, CHOL) and finding tumor in middle third of pancreatic (because of existing helicobacter pylori virus and impropriate diet). Being able to identify endangered people, one could begin treating patients and thereby, saving time, cost and increasing the rate of survivors.
\end{abstract}

Keywrds: Pancreatic cancer- retrospective- epidemiology

Asian Pac J Cancer Care, 2 (2), 25-28

\section{Introduction}

Gastrointestinal cancers are one of the most common cancers in different societies, so that in the United States after prostate cancer, the digestive tract is the second most common non-dermal cancer. Cancer of the pancreas occurs when the cells inside the pancreas that are behind the stomach begin to replicate out of control and form a mass [1-2]. These cancer cells can attack other parts of the body. There are several types of pancreatic cancer, the most common type of pancreatic adenocarcinoma, which includes $85 \%$ of cases. These adenocarcinomas begin with the part of the pancreas responsible for making digestive enzymes [4-3]. Symptoms of this type of pancreatic cancer
Submission Date: 01/18/2017 Acceptance Date: 03/10/2017

include yellowing of the skin, abdominal pain or back pain, weight loss without reason, fainting of the stool, dark urine and anorexia. Pancreatic cancer rarely occurs at the age of 40 , and more than half of the pancreatic adenocarcinomas are over 70 years old [5-6]. Risk factors for pancreatic cancer include smoking, obesity, diabetes and specific genetic conditions [7]. The pathways for pancreatic cancer diagnosis are usually the combination of these techniques: computer tomography, blood tests, and tissue samples testing [8]. To prevent pancreatic cancer, maintaining healthy weight and limiting the consumption of red meat or processed meat is recommended [9]. The likelihood of getting cancer among smokers decreases in the event of quitting, and after 20 years, the likelihood of

Corresponding Author:

Dr. Hamed Tavan

Faculty of Nursing and Midwifery, Prevention of Psychosocial Injuries Research Center, Ilam university of Medical Sciences, Ilam, Iran.

Email: hamedtavan@gmail.com 
them becoming equal to the rest of the population [10]. Treatments for pancreatic cancer include radiotherapy, chemotherapy, palliative care, or a combination of these. Each of these methods is selected according to the clinical conditions of the patient [11]. Surgery is the only remedy that can cure the disease, but it may also be used to improve the quality of life without the possibility of treatment [12]. Management of pain and gastrointestinal medications are sometimes necessary. Also, palliative care is recommended for all cases of this disease, even for those caring for treatment [13].

In 2012, all types of pancreatic cancer were the seventh cause of cancer deaths, resulting in deaths worldwide of 330,000 in that year. In the United States, pancreatic cancer is the fourth cause of death from cancer [14]. This disease occurs more often in developed countries. The pancreatic adenocarcinoma typically has a very poor prognosis. In fact, after diagnosis, $25 \%$ of people survive a year, and $5 \%$ survive for 5 years. If cancer is detected early, the five-year survival rate will increase by about $20 \%$ [15]. The city of Ilam is geographically located in the western part of Iran, and the prevalence of pancreatic cancer is among the regions with a moderate prevalence. According to the necessity of research, the researchers decided that the epidemiological study of pancreatic cancer should be investigated as a 10-year retrospective study (1394 -1385) in Ilam province.

\section{Materials and Methods}

The present study is a retrospective study of the time interval of 1395-1384 in Ilam province. The list of patients who were in the province of Ilam with pancreatic cancer was selected. Sample size and statistical society were selected based on the census. The data were collected at the Cancer Registry in Ilam and reviewed by the patients who attended the Shahid Mostafa Khomeini Hospital in Ilam and some pathological laboratories diagnosed with pancreatic cancer. The researcher designed a checklist containing several sections, the first part containing demographic information of patients (age, gender, type of cancer, educational level, occupation, place of residence, smoking and family history), the second part includes information on esophageal cancer (location) Anatomical findings, pathological findings, and lipid profiles). The researcher collected and recorded their data and placed them in special formats and entered the SPSS-V 19 for analysis of the data. The results were analyzed using descriptive statistics (frequency, mean and standard deviation) and inferential statistics (K-SCORE and ONE WAY ANOVA). Values less than 0.05 were considered as significant (P Value $<0.05$ ). At all stages of the study, the hallucinogenic principle was observed and no costs were borne by the patients. In all steps, the Helsinki rule was considered and there was no charge for patients.

\section{Results}

The statistical society of the study, which consisted of 25 people with pancreatic cancer in Ilam province during the period of 1394-1385, was the most common age group of patients with pancreatic cancer who were more than 70 years old $(60 \%)$ and men had a higher share than women (Table 1). In Figure 1, the frequency of pancreatic cancer in the province of Ilam during the period of 10 years (13451394) is shown, with the increase in the year, the number of cases was also recorded, with the highest frequency of 1394 and the lowest frequency in 2006 is. In Figure 2, the frequency of pancreatic cancer in cities is highest, with the highest frequency in the city of Ilam $(18 \%)$ and the lowest Avon (8\%).

In Table 2, the mean lipid profile (Chol, HDL, LDL, and TG) in patients studied was given with details. The frequency of pancreatic cancer based on demographic variables showed that the most group of pancreatic cancer patients was more than 70 years old and was statistically significant $(\mathrm{P}$ value $=0.00)$ and with increasing age, the incidence of pancreatic cancer also increased Find out

Table1. Distribution of Demographic Data Related to Patients

\begin{tabular}{llcc}
\hline Variables & Subgroups & Frequency & percentage \\
\hline \multirow{4}{*}{ Age } & $51-60$ & 3 & 12 \\
\multirow{5}{*}{ Gender } & $61-70$ & 7 & 28 \\
& $>70$ & 15 & 60 \\
Education level & Male & 15 & 60 \\
& Female & 10 & 40 \\
Career & Elementary school & 7 & 28 \\
& Diploma school & 7 & 28 \\
& Governmental & 11 & 44 \\
& Self- employed & 3 & 16 \\
Residency area & unemployed & 12 & 12 \\
& House keeper & 6 & 24 \\
Smoking & Urban & 13 & 52 \\
& Rural & 12 & 48 \\
Family history & Yes & 77 & 51.5 \\
& No & 73 & 48.7 \\
& Yes & 110 & 73.4 \\
& No & 40 & 26.6 \\
\hline \multirow{5}{*}{ Fo }
\end{tabular}

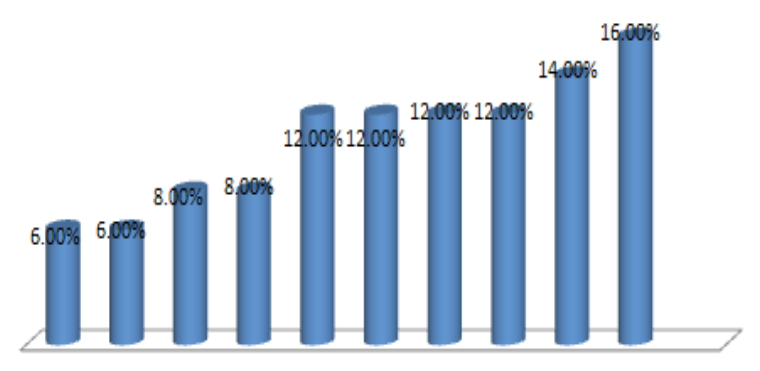

$\begin{array}{llllllllll}1385 & 1386 & 1387 & 1388 & 1389 & 1390 & 1391 & 1392 & 1393 & 1394\end{array}$

Figure1. The Frequency of Pancreatic Cancer in the Province of Ilam in the Period of 10 Years (1394-1385) shows that with increasing the number of registrations, the most frequent was 1394 and the lowest frequency is 1385 . 
Table 2. The Mean of Patients' Lipid Profile

\begin{tabular}{lccc}
\hline Profile & Number & Mean $(\mathrm{mg} / \mathrm{dl})$ & Standard Deviation \\
\hline HDL & 150 & $54 / 42$ & $61 / 11$ \\
LDL & 150 & $105 / 71$ & $42 / 35$ \\
TG & 150 & $141 / 32$ & $81 / 3$ \\
Chol & 150 & $173 / 4$ & $39 / 27$ \\
\hline
\end{tabular}

The incidence of cancer in men was higher than that of women, but it was not statistically significant ( $\mathrm{P}$ value $=0.09)$. There was a significant correlation between the area of residence and smoking and family history with the incidence of pancreatic cancer $(\mathrm{P}$ value $=0.04)$ and $(\mathrm{P}$ value $=0.03)$ and $(P$ value $=0.02)$, so that among urban residents and individuals the smoker and family history of this infection were higher.

\section{Discussion}

Nowadays, the pancreatic cancer is one of common cancer types globally which is also the sixth factor of cancer related deaths. Based on results from this study; the most general age group for having this type of cancer is people who are older than 70 years. The 41 to 50 was a lowest group in terms of incidence rate which results in the higher the age, the higher the chance of affliction. There are some similar studies both inside and outside of Iran deducting that aging may be a risk factor for pancreatic cancer because of poor diet and lacking of drinkable water $[1,17]$. Data explored from this study show that men are more in danger of getting sick which means gender is another risk factor, similar to previous analogous studies. So, based on what discussed above, men have more numbers of illness related to having full of stress careers, poor diet, more responsibilities in men and more works [4-7]. Education as another risk factor has its impact on incidence rate which people with diploma and with academic literacy had lower and higher rate of illness respectively. That shows that literacy may prevent people from getting sick or prevent to be exposed to risk factors which are similar to analogous studies [8-10]. Based on data in terms of job, unemployed people had a higher risk of getting cancer resulted from the stress of finding new job and their future led to over secretion of gastric acids and bad nutrition habits to appearance tumors in stomach [11-12]. One could conclude that having job is important factor. Data from occupancy situation imply that living in cities because of poor dietary regimen, more stress and harmful jobs would lead to increase the rate on cancer [13-14]. It seems that dwelling area is an important factor which needs more investigation about. As data derived from smoking have shown the higher level of incidence rate, one could conclude that so much carcinogens existing in cigarettes have been responsible for this outcome [15-16]. People with previous occurrence in close members of their families are the susceptible group which had the most incidence rate, so, as other similar studies have proved this matter, history is another determining factor [17-18]. As the time went on, it seemed

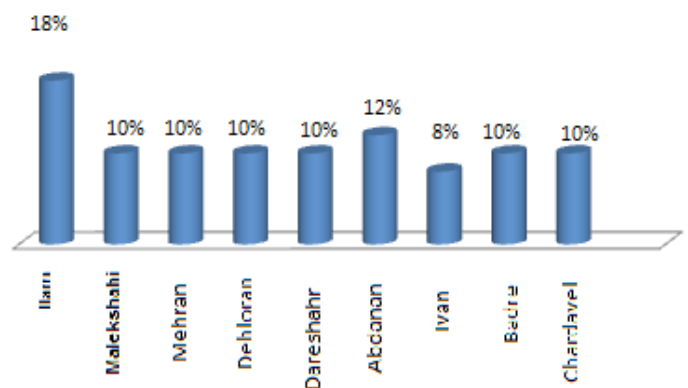

Figure 2. The Prevalence of Pancreatic Cancer in Terms of Cities Shows that the Highest Frequency is in the City of Ilam (18\%) and the Lowest Ayvan City (8\%).

that the number of new cases grew 7 to 10 times in recent years which may be because of underestimating the illness and its risk factors by people. The results of other studies show that this trend has been increasing since last decade because the nutrition and diseases were prevalent which is in a good accompany with this study $[1,19]$. In terms of anatomical site, the middle third of pancreatic had 75 cases $(50 \%)$, the last third had 45 cases $(30 \%)$ and the first third had 30 (20\%) individuals which means as the rate of tumors in middle third, related to living HPV in this region of pancreatic, is increasing every day, the other two sites undergo declination. These results are similar to previous studies done in this area [1]. The level of blood lipids was more than normal limitation, 2 or 3 times in some patients, which implies on the effect of these lipids on appearance of pancreatic cancer. Some researchers believe that poor nutrition habits are in charge of enhancing tumor bearing patients [20].

In conclusion there are retrospective studies to find out the risk factors for the presence of the disease. In this study, several effective risk factors that caused pancreatic cancer in the province of Ilam during the 10-year period (1394-1385) were found. It can be mentioned from 70 years of age, male gender, low awareness (low education), lack of job (unemployment), urbanization, smoking, inheritance (familial history), high blood lipids (LDL, TG, CHOL) as our investigated risk factors.

\section{Study restrictions}

Retrospective studies have several limitations that can be pointed out: all specimens were people who had been referred to the hospital and were diagnosed, but the number of pancreatic cancer cases may be much higher than those that may have led to hospitals. They may have had another illness and have not been diagnosed at all, the other one that has been restricted from research has not been enough to provide patients and some patients with specialized equipment, which has led to procedures that were carried out in Patients did not find enough information and entered this information.

\section{Suggestions}

Because the risk factors of the disease are detected and detected, screening can be done to identify unknown cases, and many of these patients are diagnosed at the stage of 
the onset of the disease, and initially and secondary to prevention, and the duration of treatment and diagnosis is also shorter and less costly. As well as an increase in the survival rate of the patients, as well as an effective factor in the incidence of heredity cancer, relatives and family members can also be investigated and prevented, as well as educating patients about Taking proper food and identifying with the risk factors of the disease and two One of these factors is recommended.

\section{Clinical application}

If people at risk for pancreatic cancer can be identified, they can start treatment and save time and money, as well as increase the survival rate of the affected people and take an important step in reducing mortality in cancer patients.

\section{Acknowledgment}

This research is approved by Ilam University of Medical Sciences, from the University of Medical Sciences Technology. Special thanks to deputy of research because of economic supports and to cancer registry center, to executive, conservative and archive of Shahid Mostafa Khomeini hospital for collecting data and to all whom helped us doing this study.

\section{References}

1. Ahmadloo N, Bidouei F, Omidvari Sh, Ansari M, Mosalaei A, Mohammadianpanah M. Pancreatic Cancer in Southern Iran. Iranian Red Crescent Medical Journal . 2010; 12(6):624-630.

2. Ghorbani Z, Pourshams A, Fazeltabar Malekshah A, Sharafkhah M, Poustchi H, Hekmatdoost A. Major Dietary Protein Sources in Relation to Pancreatic Cancer: a Large Prospective Study. Arch Iran Med. 2016; 19(4): 248 - 256

3. Ferlay J, Soerjomataram I, Dikshit R, Eser S, Mathers C, Rebelo M, et al. Cancer incidence and mortality worldwide: Sources, methods and major patterns in GLOBOCAN 2012. Int J Cancer. 136(5): E359 - E386.

4. Yadav D, Lowenfels AB. The epidemiology of pancreatitis and pancreatic cancer. Gastroenterology. 2013; 144(6):1252 $-1261$.

5. Bao Y, Hu FB, Giovannucci EL, Wolpin BM, Stampfer MJ, Willett WC, et al. Nut consumption and risk of pancreatic cancer in women. Br J Cancer. 2013; 109(11): 2911 - 2916.

6. Shakeri R, Kamangar F, Mohamadnejad M, , Tabrizi R, Zamani $\mathrm{F}$ and etal. Opium use, cigarette smoking, and alcohol consumption in relation to pancreatic cancer. Journal of Medicine (2016) 95:28

7. Kamangar F, Shakeri R, Malekzadeh R, et al. Opium use: an emerging risk factor for cancer? Lancet Oncol 2014; 15:e69-77.

8. Malekzadeh MM, Khademi H, Pourshams A, et al. Opium use and risk of mortality from digestive diseases: a prospective cohort study. Am JGastroenterol 2013;108:1757-65.

9. Shakeri R, Kamangar F, Nasrollahzadeh D, et al. Is opium a real risk factor for esophageal cancer or just a methodological artifact? Hospital and neighborhood controls in case-control studies. PloS One 2012; 7:e32711

10. Naghibzadeh TA, Khanjani N, Yazdi FV, et al. Opium as a risk factor for upper gastrointestinal cancers: a populationbased case-control study in Iran. Arch Iran Med 2014; $17: 2-6$.
11. Parvin M, Sabet-Rasekh P, Hajian P, Mohammadi P, Sabet-Rasekh P, Mirzaei H. Evaluating the Prevalence of the Epidermal Growth Factor Receptor in Transitional Cell Carcinoma of Bladder and its Relationship With Other Prognostic Factors. Iran J Cancer Prev. 2016 9(1):e4022.

12. Farzin L, Esmail Moassesi M, Sajadi F, Ahmadi M. Evaluation of Trace Elements in

Pancreatic Cancer Patients in Iran. Middle East Journal of Cancer 2013; 4(2): 79-86

13. Jemal A, Siegel R, Ward E, Hao Y, Xu J, Thun MJ.Cancer statistics. CA Cancer J Clin 2009;59(4):225-49.

14. Farzin L, Moassesi ME, Sajadi F, Amiri M, Shams H.Serum levels of antioxidants $(\mathrm{Zn}, \mathrm{Cu}, \mathrm{Se})$ in healthy volunteers living in Tehran. Biological trace elementresearch. Biol Trace Elem Res 2009;129(1-3):36-45.

15. Farzin L, Amiri M, Shams H, Ahmadi Faghih MA, Moassesi ME. Blood levels of lead, cadmium, and mercury in residents of Tehran. Biol Trace Elem Res2008;123(13):14-26.

16. Amaral1 AFS, Porta M, Silverman DT, Milne RL, Kogevinas M, Rothman N, et al. Pancreatic cancer risk and levels of trace elements. Gut 2012;61(11):1583-8.

17. Sara Robinson S, Solimant, Karkouri M, Gad Omer H, Joel F. Greenson. Differences in Molecular Pathologic Characteristics of Pancreatic Adenocarcinoma between Egyptian and Moroccan Patients. Middle East Journal of Cancer 2010; 1(1): 27-36

18. Mohamadkhani A, Akbari MR, Ghanbari R, Naderi E, Rezanejad-Asl P, Pourshams A. Direct Sequencing of Cyclooxygenase-2 (COX-2) Revealed an Intronic Variant rs201231411 in Iranian Patients with Pancreatic Cancer. Middle East J Dig Dis 2015;7:14-8.

19. Epanlou SG, Malekzadeh F, Naghavi M, Forouzanfar M, Shahraz S, Moradi-Lakeh M, Malekzadeh R, Poustchi H. Trend of Gastrointestinal and Liver Diseases in Iran: Results Of the Global Burden of Disease Study, 2010. Middle East J Dig Dis 2015;7:121-37.

20. Shakeri R, Malekzadeh R, Etemadi A, Nasrollahzadeh D, Aghcheli K, Sotoudeh M, et al. Opium: an emerging risk factor for gastric adenocarcinoma

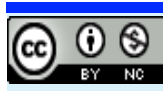

This work is licensed under a Creative Commons AttributionNon Commercial 4.0 International License. 